\title{
Statistical Methods for Effectiveness Estimation of Municipal Institutions
}

\author{
E. Yu. Chemezova, K. A. Zaykov \\ Department of Statistics, Novosibirsk State University of Economics and Management, Novosibirsk, Russian \\ Federation \\ Email: chemezova@inbox.ru
}

Received 28 July 2014; revised 30 August 2014; accepted 12 September 2014

Copyright $@ 2014$ by authors and Scientific Research Publishing Inc.

This work is licensed under the Creative Commons Attribution International License (CC BY). http://creativecommons.org/licenses/by/4.0/

(c) (i) Open Access

\begin{abstract}
Municipal institutions operate in all sectors of the urban economy, creating jobs, providing services, and creating income for their own development and the municipal budget. Market environment and innovative vector of megapolis development include the establishment municipal institutions and improve the forms of their activities. One of the strategic objectives for the government is to increase the effectiveness of municipal institutions. Problems integrated estimation of these institutions are under intense scrutiny of statistical science in management decisions. This paper discussed the problems of effectiveness estimation of municipal institutions and proposed a new approach to solving this task.
\end{abstract}

\section{Keywords}

Municipal Institutions, Socio-Economic Systems, Effectiveness Estimation, Typology, Typological Grouping, Multidimensional Average, Multiplicative Effect, Balanced Scorecard

\section{Relevance of Research}

Objectives of socio-economic development of municipalities require reasonable management decisions, which should be based on a clear understanding of the current status and potential of the territory. In this regard, the need for information about the socio-economic status and development of municipalities increases.

Russian Federation has already taken important steps to improve the effectiveness of all levels of government, in particular the reform of local government. In article 17 of the Federal law No. 131-FZ "On general principles of organization of local government in Russian Federation", which entered into force on 1 January 2009, it is written about the powers of local governments by the decision of questions of local significance, including the collection of statistical reporting [1]. 
In a modern market economy large municipal formations are developing dynamically. In these conditions the issues of functioning and management of institutional units are extremely important, both as a whole and at the level of municipal institutions.

The effect of the activity of municipal institutions is considered in two aspects: economic and social.

The economic effect consists in satisfying the public demand for municipal services, creating jobs, attracting subsidies and increasing the investment attractiveness. Social effect of activity of municipal institutions designed for all residents of municipalities. Social effect increases the quality public services, social support, and level of living of the population.

Study of economic and social effects allows estimating multiplicative effect of activity of municipal institutions on the territory's economy [2].

So estimation of the effectiveness of municipal institutions, in our opinion, promotes the adoption of reasonable management decisions and increases the economic and social effects of activity of municipal institutions.

\section{Problematic, Setting Tasks}

One of the strategic objectives for the government of the municipality is improving the effectiveness of municipal institutions. As is known, the collection, processing and analysis of information at the municipal level is provided by municipal statistics. In this regard problem of complex estimates of institutions at this level are the subject of intense scrutiny of statistical science in the sphere of management decisions.

Currently there is no uniform formalized methodology for effectiveness analysis of municipal institutions. Every subject of Federation has the right to establish its list of evaluation indicators, based on the needs of operational management and economic activities. Municipal institutions operate in most sectors of the economy and their heterogeneity often leads to incompatibility of scorecards, which complicates comparative evaluation.

In this regard, research on the development of a uniform methodology for estimation the effectiveness of municipal institutions is actual.

Taking into account branch features of municipal institutions and the factors that influence their activities was designed the following approach to estimation of effectiveness. The general scheme of a statistical study of activities of municipal institutions is shown in Figure 1.

For monitoring the activities of municipal institutions could be used the following information: a list of municipal services, approved parameters of quality of municipal services, complaints of consumers of municipal services, data of statistical reporting, the results of sociological research, reports on the execution of the municipal tasks, the results of the assessment activities.

Monitoring can be done in the following ways: special sample surveys research, population survey on the quality of municipal services; comparative analysis of actual and planned values of quantitative and qualitative indicators of municipal tasks; direct observation and on-site inspections.

Ways to monitor the implementation of municipal tasks are carried out by authorized agencies of local selfgovernment.

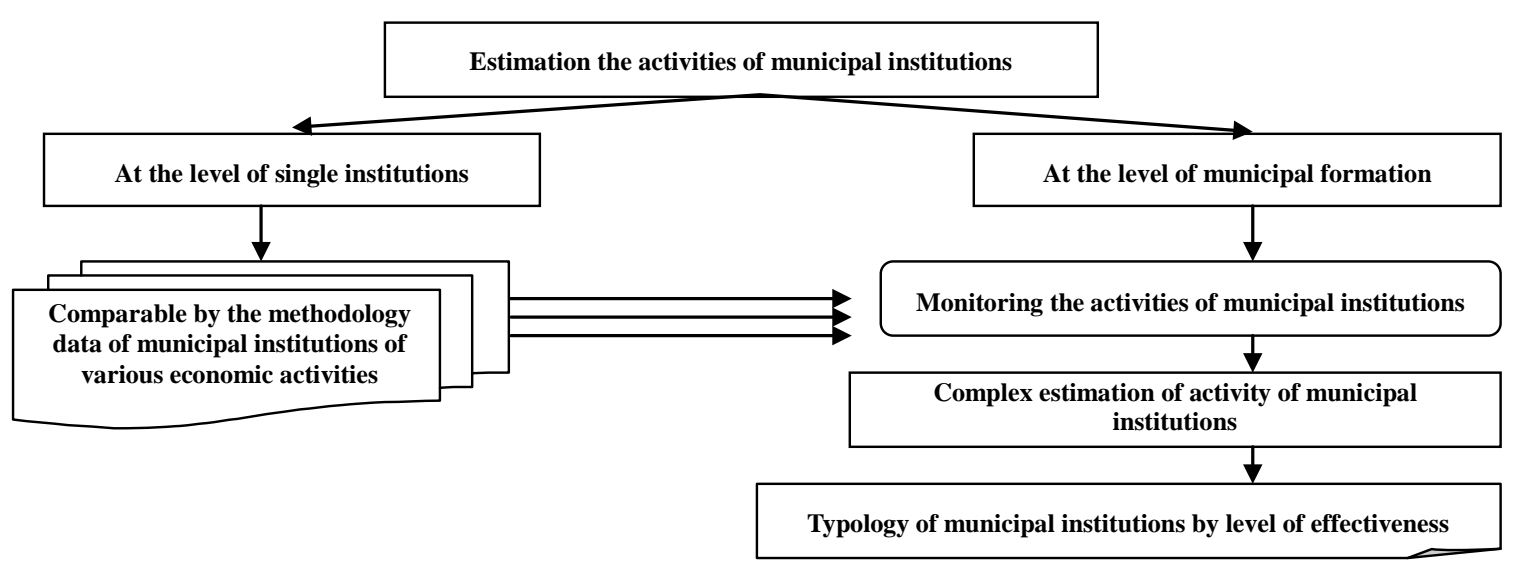

Figure 1. Estimation the activities of municipal institutions. 


\section{Methodology and System of Indicators}

Even in the 90s of 20th century in the economic literature was conducted discussion about methods of estimation effectiveness of organizations activities. In 1992, R.S. Kaplan and D.P. Norton developed the Balanced Scorecard (BSC), which included not only financial information, but other indicators of internal and external environment of the enterprise. This system can be used to estimate enterprises of various spheres of activity.

The advantage of the BSC in the practice of statistical analysis consists in aggregating large data set describing the various objects of research.

Although that BSC was designed to commercial enterprises, the concept is widely used in the public sector. Municipal institution is a multifaceted research object, which is different from a commercial enterprise by the purpose and objectives of the operation, however, has similar components management strategy. According to this model, a comparative evaluation of municipal institutions can be conducted on the following directions: indicators of the financial component, internal business processes, client side, staffing [3].

An array of indicators based on these directions can be used to construct the integral parameters. Further, such parameters can be used for typology of municipal institutions by level of effectiveness.

Feature of such data set are incomparability on units of measurement and multidirectional of their influence on the effectiveness of institutions. These disadvantages can be eliminated in various ways [4].

Multidirectional influence is eliminated by replacing the sign on the opposite on those characteristics that negatively influence on the effectiveness of institutions (for example, indicators of the proportion complaints of consumer services, the proportion of low-quality services, etc.).

To get away from the different units of measurement is the procedure of standardization (or normalization) indicators (Equations (1) and (2)):

or

$$
x_{i j}^{\mathrm{norm}}=\frac{x_{i j}}{\max _{j} x_{i j}}
$$

$$
x_{i j}^{s t}=\frac{x_{i j}-\bar{x}_{j}}{\sigma_{j}}
$$

where $x_{i j}^{\text {norm }}$-normalized value of $j$-th parameter, which has the $i$-th object; $x_{i j}^{s t}$-standardized value of $j$-th parameter, which has the $i$-th object;

$\bar{x}_{j}$-the average value of the $j$-th integral parameter;

$\sigma$-root mean square (standard deviation) of $j$-th parameter;

$i$-object number (in our case-municipal institutions);

$j$-parameter number.

For practical realization of this procedure can be used a software package, for example, STATISTICA.

Because the municipal institution characterized by a complex parameters so typology for institutions is expedient to use the integral indicator.

Method of multidimensional average deserves attention as an original interpretation of the multivariate analysis and the method of data compression. For each element of a statistical aggregate (institutions) can be calculated average ratio characterizing this element by some group characteristics. Such conditional indicator called multidimensional average.

Calculation of multidimensional average allows making the transition from the multi-dimensional space of attributes to one-dimensional. The main condition for the calculation —an array of standardized (normalized) indicators (Equation (3)):

$$
\bar{P}_{i}=\frac{1}{k} \sum_{j=1}^{k} x_{j}^{s t},
$$

where $x_{j}^{\text {st }}$-standardized or normalized value of $j$-th parameter;

$k$-amount of parameters;

$i$-number of municipal institutions.

At work with an array of information multidimensional average serves as an integral indicator, which can be used for the distribution of municipal institutions in groups. 
Offered normalize the raw data by the maximum value. In this case, the multidimensional average values will range from 0 to 1 [5].

Then the critical point of the transition institutions from one qualitative state to another determined on the basis of partition of the set of values of integral indicator into three equal intervals: 0 - 0.33-low effectiveness; 0.33 - 0.67—average effectiveness; 0.67 - 1.0—high effectiveness [2] [6] [7].

\section{Implementation the Methodology}

The proposed methodology was adapted for the investigation of the effectiveness of such municipal institutions as secondary schools, lyceums and gymnasiums in Novosibirsk City (Russian Federation).

In Russia, there are three types of schools. Gymnasiums and lyceums have greater autonomy than regular schools, so it was decided to study them separately.

For assessment was formed on database aggregated materials of departmental statistics. All indicators were normalized to the maximum values (Equation (1)). Based on the normalized data was calculated multivariate average (Equation (3)). Such multidimensional average was used as integral indicator of the level of effectiveness. Using it were formed three equal intervals: 0 - 0.33-low effectiveness; 0.33 - 0.67-average effectiveness; 0.67 - 1.0-high effectiveness (Table 1).

Among the total number of schools, gymnasiums and lyceums of Novosibirsk can be seen that the largest share have institutions with an average efficiency (Figure 2).

This methodology of effectiveness estimation of municipal institutions allows solving several problems:

1) Definition groups of indicators characterizing the effectiveness of municipal institutions. Create an information base for decision-making in the management of local government agencies (the need for additional subventions unreasonableness functioning institutions, the ability to identify inefficient municipal institutions).

2) Providing comparability of data about the activity of municipal institutions. Creating a unified methodology for estimating the effectiveness of the municipal institutions of different sectoral focus.

3) Complex estimation of activity municipal institutions (typology of municipal institutions by level of effectiveness) as a basis for decision-making management and strategic planning of the municipalities.

4) Possibility of continuous monitoring of the activities of municipal institutions and conducting measures to improve their performance.

Table 1. Distribution of secondary schools, lyceums and gymnasiums in Novosibirsk City by level of effectiveness for 20132014.

\begin{tabular}{|c|c|c|c|c|}
\hline \multirow[b]{2}{*}{ Level of effectiveness } & \multicolumn{2}{|c|}{ Lyceums and gymnasiums } & \multicolumn{2}{|c|}{ Secondary schools } \\
\hline & $\begin{array}{l}\text { Number of municipal } \\
\text { institutions, units }\end{array}$ & Proportion, \% & $\begin{array}{l}\text { Number of municipal } \\
\text { institutions, units }\end{array}$ & Proportion, \% \\
\hline Low effectiveness & 13 & 35.1 & 59 & 42.8 \\
\hline Average effectiveness & 23 & 62.2 & 78 & 56.5 \\
\hline High effectiveness & 1 & 2.7 & 1 & 0.7 \\
\hline Total & 37 & 100.0 & 138 & 100.0 \\
\hline
\end{tabular}

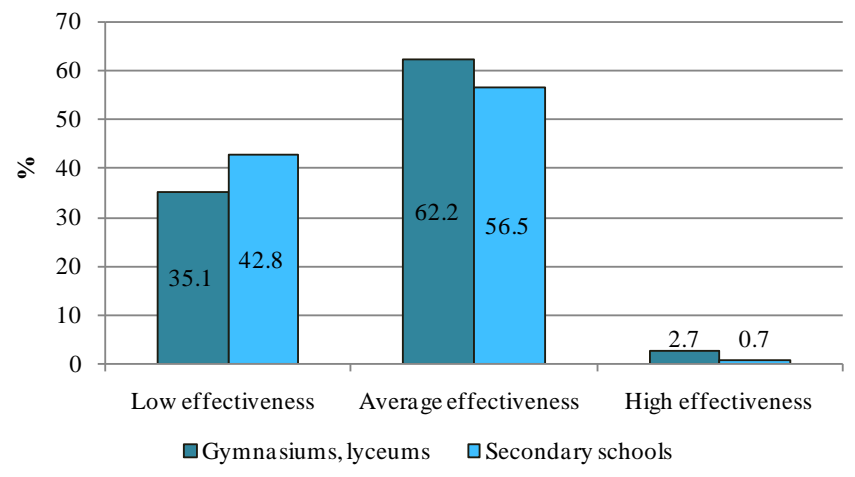

Figure 2. Distribution of municipal institutions in Novosibirsk City by level of effectiveness for 2013-2014. 


\section{Conclusions}

The developed methodology of effectiveness estimation of municipal institutions can be used by governments of municipalities Russian Federation to management decisions in the socio-economic development of the territories. It allows conducting a comprehensive audit and optimization of existing municipal institutions of culture, sports, health, education and others in the Russian Federation.

The proposed methodology is universal and easily for transformation to the needs of the state and municipal levels of government.

\section{Acknowledgements}

The paper was performed according to the results of grant project on competition of Novosibirsk Municipality for Grants to young scientists and engineers in the field of innovation in 2014 "Development of methodology for effectiveness estimation of municipal institutions”.

\section{References}

[1] Federal Law No. 131-FZ 1 (2009) On General Principles of Organization of Local Government in Russian Federation.

[2] Glinskiy, V.V., Serga, L.K. and Scherbak, I.V. (2012) Estimation of Tourism Multiplier Effect at the Regional. Statistical Studies, 1, 48-52.

[3] Kaplan, R.S. and Norton, D.P. (1992) The Balanced Scorecard: Measures That Drive Performance. Harvard Business Review, January/February, 71.

[4] Shapkharova, N.I. and Chemezova, E.Yu. (2009) Social and Economical Typology of Municipal Formations of a Region. Siberian Financial School, 3, 28-33.

[5] Glinskiy, V.V. (2008) Statistical Methods to Support Management Decisions: Monograph. Publishing NSUEM, Novosibirsk.

[6] Glinskiy, V.V. and Chemezova, E.Yu. (2012) On Convergence of Main Concepts of Typology of Social-Economic Studies Data. Vestnik NSUEM, 2, 67-73.

[7] Chemezova, E.Yu. (2013) Statistical Methods in the Solution of the Applied Problems of the Development of Territory. Vestnik NSUEM, 4, 153-165. 
Scientific Research Publishing (SCIRP) is one of the largest Open Access journal publishers. It is currently publishing more than 200 open access, online, peer-reviewed journals covering a wide range of academic disciplines. SCIRP serves the worldwide academic communities and contributes to the progress and application of science with its publication.

Other selected journals from SCIRP are listed as below. Submit your manuscript to us via either submit@scirp.org or Online Submission Portal.
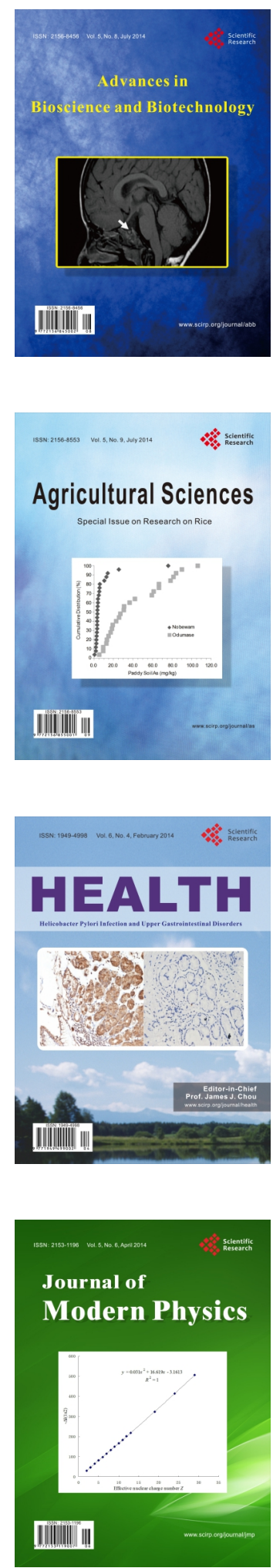
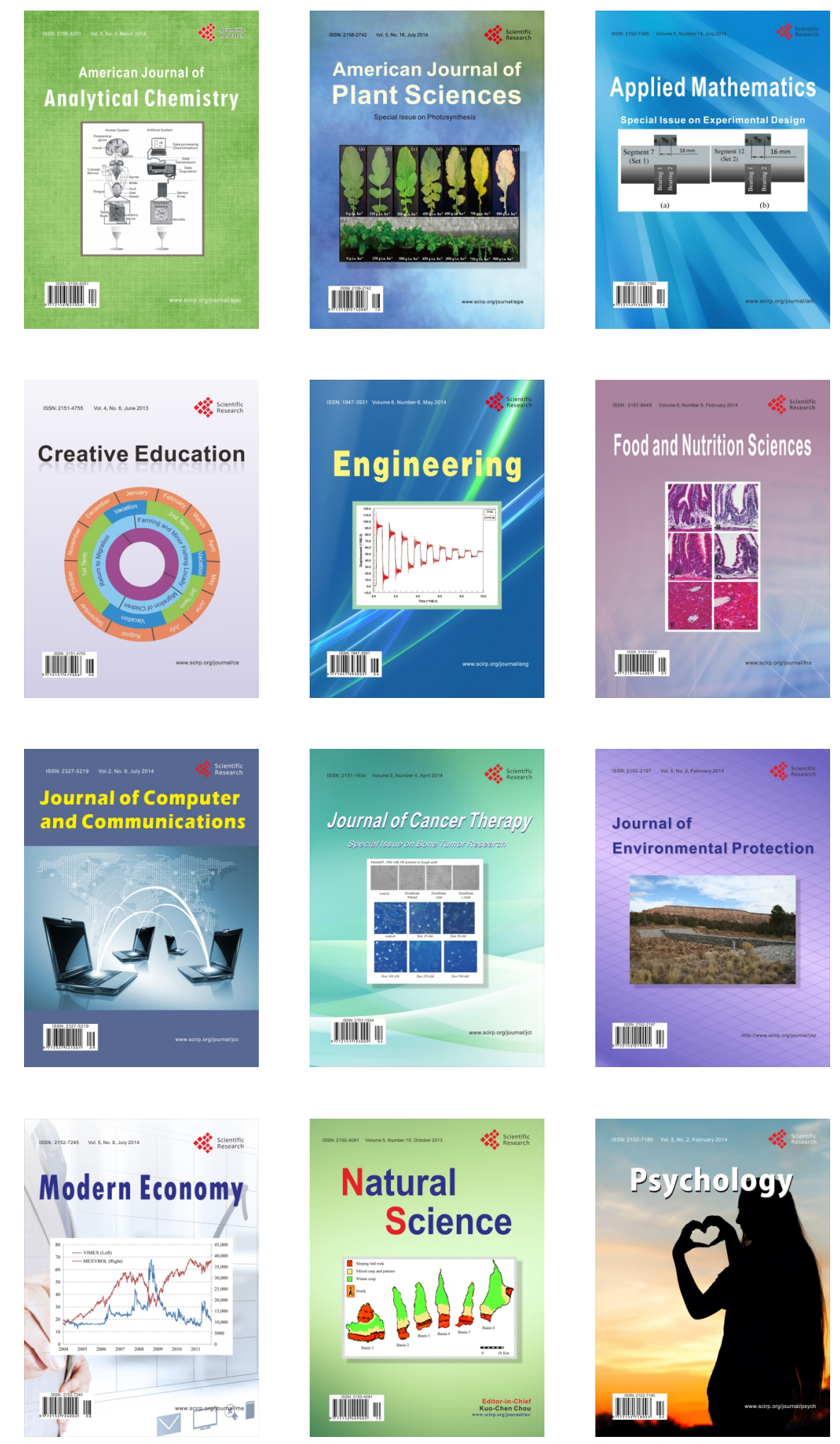